\title{
Retrospective Lymphoma Study from Malaysia Private Hospital
}

\author{
Dayang Sharyati Datu Abdul Salam ${ }^{1,2}$, Teoh Siew-Hoon ${ }^{1}$, Peh Suat-Cheng ${ }^{3}$ and Cheah Shiau-Chuen ${ }^{1^{*}}$ \\ ${ }^{1}$ Faculty of Medicine and Health Sciences, UCSI University, Jalan Menara Gading, Kuala Lumpur, Malaysia \\ ${ }^{2}$ Department of Pathology and Biomedical Science, University of Otago, Dunedin, New Zealand \\ ${ }^{3}$ Sunway University Hospital, Jalan Universiti, Bandar Sunway, Malaysia

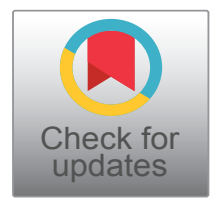

*Corresponding author: Cheah Shiau-Chuen, Faculty of Medicine and Health Sciences, UCSI University, No.1, Jalan Menara Gading, UCSI Heights, 56000 Cheras, Kuala Lumpur, Malaysia, Tel: 603-9101-8880; 603-9102-2288, Fax: 603-9101-1068

\begin{abstract}
Background: Lymphoma is a malignant disease of the immune system with the most rapidly increasing incidence in many countries. According to 2008 WHO classification, lymphoma can be classified according to: Hodgkin lymphoma or non-Hodgkin lymphoma, B-cell or T-cell and the site from which the cell arises. This classification system is important because it affects treatment and prognosis. There are numerous subtypes of NHL which is a reflection of the complex growth and differentiation of the type of lymphocytes they developed in. This study aimed to elucidate the incidence and prevalence of lymphoma encountered in a private service hospital in Kuala Lumpur (KL), Malaysia.
\end{abstract}

Materials and methods: A total of 210 patients' records were retrieved from the archives of Pantai Hospital KL, from 2010 to 2015 . The histopathology slides were reviewed and confirmed according to the WHO proposed scheme. Immuno-histochemical staining with a panel of lymphoid antibodies was performed accordingly and data were categorized and statistically analyzed.

Results: Among the 210 patients, 55\% were males and $45 \%$ were females. There were $27 \%$ Malays, $53 \%$ Chinese and $8 \%$ Indians. The ages of patients ranged from 8 to 92 years with a mean age of 51 years. $46 \%$ of the cases were nodal tissue with the most common lymphoma encountered was Diffuse Large B-cell Lymphoma (51\%), Follicular-lymphoma (10\%) and Marginal Zone Lymphoma (7.6\%).

Conclusion: Significant difference was found in terms of ethnicities ( $p=0.046$ ) with patients' age group. Further studies can help to better understand the underlying differences in the multi-ethnic population of Malaysia.

\section{Keywords}

Hodgkin's lymphoma, Non-Hodgkin's lymphoma, Incidence, Prevalence, Malaysia

\section{Introduction}

Lymphoma is a type cancer that originates by the malignant transformation of lymphocytes in the lymphatic system. The lymphoma classification system [1] according to 2008 World Health Organization (WHO) shows that $85 \%$ of lymphoma came from non-Hodgkin lymphoma (NHL) of B-cell lineage and can be simply divided into indolent, or slow growing types and aggressive types. The key points of NHL classification are the cell size and nodal architecture, whether small cell or large cell; follicular or diffuse pattern are performed. The principles are diffuse and large cell are more aggressive while follicular and small cell are more indolent [2]. This classification system is important because it helps to determine patients' treatment and prognosis. There are numerous subtypes of NHL which is a reflection of the complex growth and differentiation of the type of lymphocytes they developed in [1]. The major subtypes are B-cell lymphoma and T-cell/NK-cell lymphoma. Since it is still not possible to select a specific treatment for each type of NHL, NHL is generally divided into major subgroups namely indolent types for example Follicular Lymphoma (FL), aggressive types such as Diffuse Large B-cell Lymphoma (DLBCL) and Burkitt Lymphoma (BL). Most of NHL cases arise at the lymph nodes or known as the nodal area. However, there were about $25-50 \%$ cases whereby the lymphoma originates elsewhere, and these are known as the extranodal sites [3]. Some of the common extranodal sites are the gastrointestinal tract, bone and oral.

$\mathrm{NHL}$ is the tenth most common cancer worldwide 
with $2.7 \%$ of the total cancer diagnosed in 2012, which is approximately 390,000 and ranks seventh among the developed countries [4]. It is the eleventh most common cancer in Europe and has the highest incidence rate in North America, Europe and Australasia. While South Central Asia has the lowest incidence rate [5], showing that the incidence for NHL varies by geographic region. NHL commonly affected individuals aged more than 60-years-old with males having more tendencies to contract NHL. In USA, Caucasians are more at risked for developing the NHL than African Americans [6]. DLBCL by far the biggest category amongst the NHL is known to be heterogeneous with variable outcome to treatment. DLBCL accounts for approximate $30-40 \%$ while other common NHL subtypes like FL, BL or Marginal Zone Lymphoma (MZL) accounts for approximately 20\%, 3\% and $12 \%$ respectively from the total of all NHLs in the Western countries [1].

In Malaysia, NHL was the ninth most common cancer according to International Agency for Research on Cancer (IARC) estimated cancer incidence in 2012 [7]. Malaysia is a unique country consist of multi-racial and ethnicity such as Malay, Chinese and Indian that makes it interesting to study pathophysiology of diseases. It was found that Chinese have higher incidence rate compared to Malays and Indian ethnics of Malaysia and also lymphoma incidence was slightly higher in males than females among the 776 lymphoma cases diagnosed and registered at 2007 Malaysia National Cancer Registry [8]. In a Malaysian series from a single medical center, DLBCL was found to constitute approximately $46 \%$ of all cases of NHLs seen [9].

The pathology of lymphoma and increase in incidence remains largely unexplained. In the past, the identification of NHL risk factors has been hindered by the complexity nature of the diseases, inappropriate subtype classification or difference in the diagnostic method. While, survival rates for NHL vary widely, depending on the type of $\mathrm{NHL}$, stage, age of the patient, and other variables. Since Malaysia is a country with multi-ethnic community, it is of interest to consider variations in the incidence of NHL among different populations across the world. However, studies on cancer incidence particularly NHL in Malaysia is scarce and the information on cancer prevalence was not up to date. Hence, the overall aim of this study was to elucidate the incidence and prevalence of malignant lymphoma in the multi-ethnic population of Malaysia. In this retrospective study, the patient's data collected from Pantai Hospital Kuala Lumpur was evaluated to describe the epidemiology and of malignant lymphoma in Malaysia in the period from 2010 and 2015.

\section{Patients and Methods}

\section{Patients' selection}

Data concerning all patients diagnosed as malignant lymphoma reports were retrieved from Pantai Premier Pathology archives from January 1, 2010 to December 31,2015 . The demographic data of these patients, immunohistochemistry slides and biopsy were obtained from the Pantai Premier Pathology database by the referring clinician. All the lymphoma were sections at 4 $\mu \mathrm{m}$ for immune-histochemical staining using a panel of monoclonal and polyclonal antibodies according to Pantai Premier Pathology's standard operating procedure. The studies complied with all provisions of the Declaration of Helsinki and were approved by Medical Research Ethics Committee Malaysia and UCSI University Faculty of Medicine and Health Science Ethics Committee.

\section{Data analysis}

Results are expressed as mean, number and percentage using Microsoft Excel 2010 (USA). They were categorized according to lymphoma subtypes (HL and NHL subtypes), site of presentation (nodal or extranodal), age presentation groups ( $<20$ years, 20 to $<30,30$ to $<$ 40,40 to $<50,50$ to $<60,60$ to $<70,>70$ ), gender (male or female) and ethnicity (Chinese, Malay, Indian, Others inclusive Bumiputera (indigenous) and foreigners with undetermined country of origin). Statistical analysis was performed using GraphPad Prism software (version 5.0; GraphPad Software Inc., San Diego, CA). $\chi^{2}$ and/or Fisher's exact tests were used for categorical parameters to identify significant relationships between variables. $P$ values $<0.05$ were considered statistically significant.

\section{Results}

\section{Lymphoma subtypes and site of presentation}

Of the 210 cases of malignant lymphomas reviewed, there were a total of $25(12 \%)$ cases of $\mathrm{HL}$ compared to $185(88 \%) \mathrm{NHL}$ cases with the ratio for $\mathrm{HL}$ to $\mathrm{NHL}$ were 1:7. For $\mathrm{HL}$, classical $\mathrm{HL}$ was the most common with 22 cases $(88 \%)$ while there were 3 cases $(12 \%)$ of Lymphocyte predominant nodular HL. The most prevalent B-cell $\mathrm{NHL}$ in this series was DLBCL not otherwise specified (NOS) with a total of 107 cases (51\%) followed by 21 cases (10\%) of Follicular Lymphoma (FL), 16 cases (7.6\%) of MZL, 4 cases (1.9\%) of Plasmablastic Lymphoma, 6 cases $(2.9 \%)$ of BL, 6 cases (2.9\%) of Mantle Cell Lymphoma (MCL), 3 cases (1.4\%) of Small Lymphocytic Lymphoma (SLL), 3 cases (1.4\%) of Lymphoblastic Lymphoma and 9 cases (4.3\%) of B-cell NHL with no specific category. In addition, there were a total of 10 cases (5\%) of T-cell NHL.

Among the 210 cases, 96 (46\%) originated from the nodal sites while remaining 114 cases (54\%) were extranodal sites. The common extranodal sites was gastrointestinal tract with 31 cases $(27 \%)$, Waldeyer ring with 15 cases (13\%) followed by both thyroid and mediastinal with 10 cases each (9\%) and other sites (48 cases, 41\%). Figure 1 showed the common extranodal sites found among the lymphoma patients in this study. 


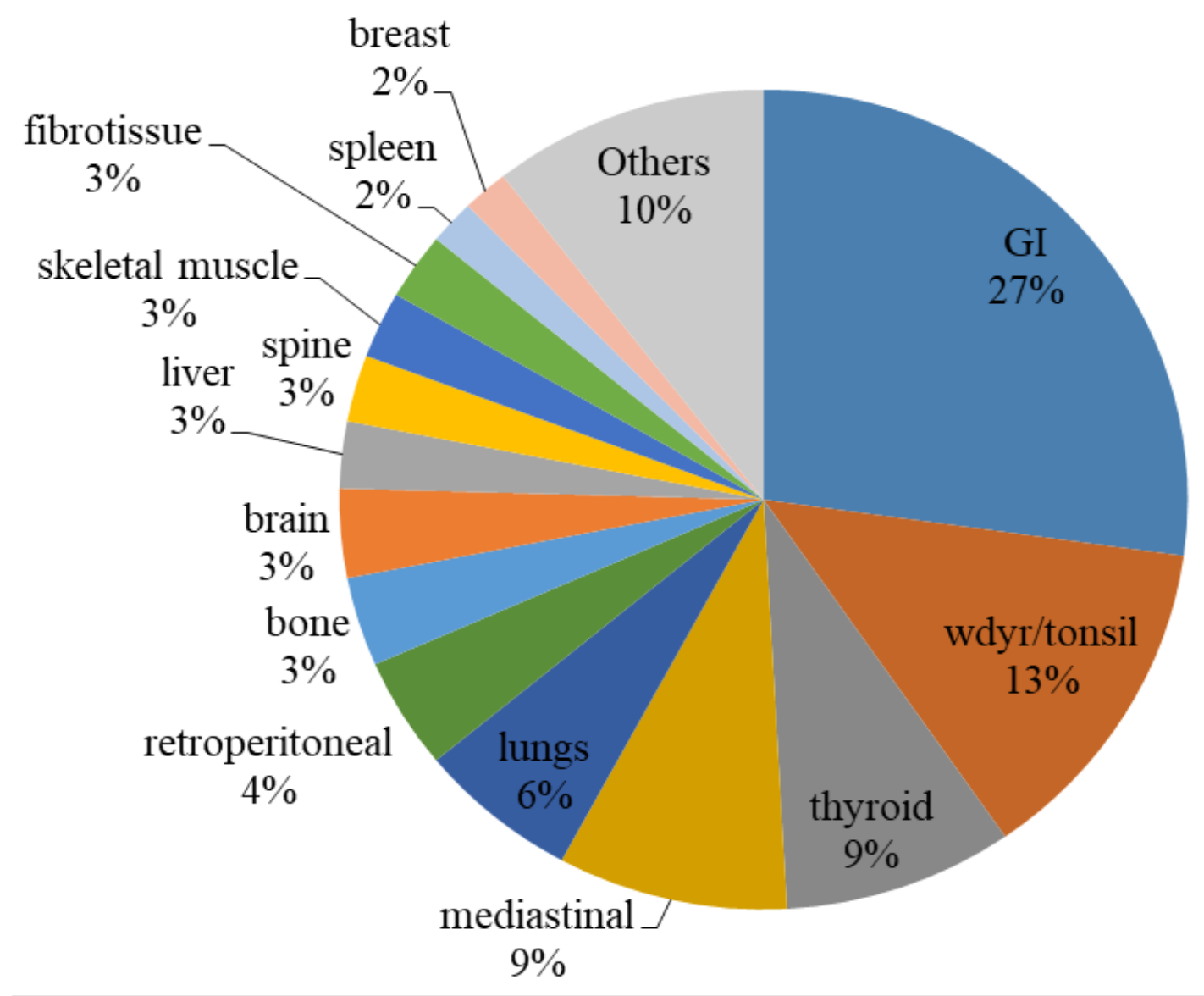

Figure 1: Lymphoma extranodal sites among Malaysian patients in 2010-2015.

\section{Age presentation groups}

The patients' age presentation groups are summarized in Table 1. Among the 7 age presentation groups, the highest cases was recorded in the age group 50 to $<60$-years-old with 53 cases ( $25.2 \%)$, followed by 60 to $<70$ years with 46 cases (21.9\%), 30 cases (14.3\%) in 40 to $<50$ age group, 29 cases $(13.8 \%)$ in $>70$ age group, 22 cases $(10.5 \%)$ each for 20 to $<30$ and 30 to $<40$ age groups and lastly 8 cases $(3.8 \%)$ in $<20$ years group. In all the age group except 20 to $<30$ years, there were more male than female or same amount of number for both male and female in two of the age groups: 30 to $<40$ and 60 to $<70$. However, there was no significant difference found for age presentation group in relation to gender $(p=0.791)$.

A significant difference was detected between the age presentation group and the Malaysian ethnics ( $p$ $\left.=0.046^{*}\right)$. Chinese was the highest ethnic in all the age group presentation except for two age groups: $<20$ years and 20 to $<30$ years, which recorded Malay as the highest ethnic. In terms of highest recorded cases for each ethnic with regards to the age group: Chinese had the highest in $>70$ years age group with $62.1 \%$, Malay ethnic in the 20 to $<30$ years with $59.1 \%$, Indian ethnic with $20 \%$ in the 40 to $<50$ years age group while for Others was in 40 to $<50$ years with $16.7 \%$. For site of lymphoma, extranodal had more cases than nodal sites except for the age 50 to $<60$ years age group and two other age group ( 20 to $<30$ years and 60 to $<70$ years) which both of nodal and extranodal sites had similar amount number of cases. However, there was no significant association found in terms of lymphoma site and the age presentation groups $(p=0.178)$.

In terms of lymphoma subtype, DLBCL NOS had the most cases in $>70$ years age group with $69 \%$ (20 cases) compared to other age groups but the increasing cases were first seen from age group 50 years and above with 30 cases. FL had the highest cases in 40 to $<50$ age group and 50 to $<60$ years group with 8 cases each. MZL had the most cases in 60 to $<70$ years with 6 cases while $\mathrm{MCL}$ cases were all seen in the age group more than 50 years ( 50 to $<60,60$ to $<70$ and $>70$ age group). The most cases seen for $\mathrm{BL}$ was in the $<20$ years age group with 3 cases (37.5\%) while none was found in the age group more than 50-years-old. For T-cell NHL cases, most was found grouping between 40 to 69 -yearsold group. While for $\mathrm{HL}$, most cases were found below 30-years-old with 17 cases out of the 25 total cases.

Further analysis was done to display the patients' data according to NHL risks factors which was found to be more common in $\geq 60$ years age group. There were 75 patients for above 60 -years-old group with more males $(52 \%)$ than females (48\%) with median age of 68.09 . The common lymphoma site was extranodal with $56 \%$ while 
Table 1: Age presentation group analyses.

\begin{tabular}{|c|c|c|c|c|c|c|c|}
\hline & $\begin{array}{l}<20 \text { years } \\
N=8\end{array}$ & $\begin{array}{l}20 \text { to }<30 \\
N=22\end{array}$ & $\begin{array}{l}30 \text { to }<40 \\
N=22\end{array}$ & $\begin{array}{l}40 \text { to }<50 \\
N=30\end{array}$ & $\begin{array}{l}50 \text { to }<60 \\
N=53\end{array}$ & $\begin{array}{l}60 \text { to }<70 \\
N=46\end{array}$ & $\begin{array}{l}>70 \\
N=29\end{array}$ \\
\hline \multicolumn{8}{|l|}{ Gender $(p=0.791)$} \\
\hline Female & $3(37.5)$ & $12(54.5)$ & $11(50.0)$ & $11(36.7)$ & $21(39.6)$ & $23(50.0)$ & $13(44.8)$ \\
\hline Male & $5(62.5)$ & $10(45.5)$ & $11(50.0)$ & $19(63.3)$ & $32(60.4)$ & $23(50.0)$ & $16(55.2)$ \\
\hline \multicolumn{8}{|l|}{ Ethnic $\left(p=0.046^{*}\right)$} \\
\hline Chinese & $3(37.5)$ & $7(31.8)$ & $11(50.0)$ & $15(50.0)$ & $29(54.7)$ & $28(60.9)$ & $18(62.1)$ \\
\hline Malay & $4(50.0)$ & $13(59.1)$ & $7(31.8)$ & $4(13.3)$ & $14(26.4)$ & $12(26.1)$ & $4(13.8)$ \\
\hline Indian & $0(0.0)$ & $0(0.0)$ & $1(4.5)$ & $6(20.0)$ & $5(9.4)$ & $1(2.2)$ & $3(10.3)$ \\
\hline Others & $1(12.5)$ & $2(9.1)$ & $3(13.6)$ & $5(16.7)$ & $5(9.4)$ & $5(10.9)$ & $4(13.8)$ \\
\hline \multicolumn{8}{|l|}{ Site $(p=0.178)$} \\
\hline Nodal & $2(25.0)$ & $11(50.0)$ & $6(27.3)$ & $14(46.7)$ & $30(56.6)$ & $23(50.0)$ & $10(34.5)$ \\
\hline Extranodal & $6(75.0)$ & $11(50.0)$ & $16(72.7)$ & $16(53.3)$ & $23(43.4)$ & $23(50.0)$ & $19(65.5)$ \\
\hline \multicolumn{8}{|l|}{ Lymphoma Subtype } \\
\hline DLBCL, NOS & $2(25.0)$ & $6(27.2)$ & $12(54.5)$ & $9(30.0)$ & $30(56.6)$ & $28(60.9)$ & $20(69.0)$ \\
\hline Plasmablastic & $1(12.5)$ & $0(0.0)$ & $0(0.0)$ & $1(3.3)$ & $1(1.9)$ & $0(0.0)$ & $1(3.4)$ \\
\hline $\mathrm{FL}$ & $0(0.0)$ & $0(0.0)$ & $1(4.5)$ & $8(26.7)$ & $8(15.1)$ & $4(8.7)$ & $0(0.0)$ \\
\hline MZL & $0(0.0)$ & $0(0.0)$ & $3(13.6)$ & $2(6.7)$ & $2(3.8)$ & $6(13.0)$ & $3(10.3)$ \\
\hline MCL & $0(0.0)$ & $0(0.0)$ & $0(0.0)$ & $0(0.0)$ & $2(3.8)$ & $2(4.3)$ & $2(6.9)$ \\
\hline $\mathrm{BL}$ & $3(37.5)$ & $0(0.0)$ & $2(9.1)$ & $1(3.3)$ & $0(0.0)$ & $0(0.0)$ & $0(0.0)$ \\
\hline SLL & $0(0.0)$ & $0(0.0)$ & $0(0.0)$ & $1(3.3)$ & $1(1.9)$ & $1(2.2)$ & $0(0.0)$ \\
\hline $\begin{array}{l}\text { Lymphoblastic } \\
\text { Lymphoma }\end{array}$ & $0(0.0)$ & $0(0.0)$ & $1(4.5)$ & $0(0.0)$ & $1(1.9)$ & $0(0.0)$ & $1(3.4)$ \\
\hline B-cell NHL (No category) & $0(0.0)$ & $1(4.5)$ & $1(4.5)$ & $2(6.7)$ & $2(3.8)$ & $1(2.2)$ & $2(6.9)$ \\
\hline T-cell NHL & $0(0.0)$ & $0(0.0)$ & $1(4.5)$ & $3(10.0)$ & $4(7.5)$ & $2(4.3)$ & $0(0.0)$ \\
\hline $\mathrm{HL}$ & $2(25.0)$ & $15(68.2)$ & $1(4.5)$ & $3(10.0)$ & $2(3.8)$ & $2(4.3)$ & $0(0.0)$ \\
\hline
\end{tabular}

Table 2: Gender analyses.

\begin{tabular}{|l|l|l|}
\hline & $\begin{array}{l}\text { Male } \\
\mathbf{N}=116(\%)\end{array}$ & $\begin{array}{l}\text { Female } \\
\mathbf{N}=94 \\
\text { Age }\end{array}$ \\
\hline Median (Range) & $51.3(8-80)$ & $51.1(8-92)$ \\
\hline Ethnic $(\boldsymbol{p}=\mathbf{0 . 8 3 9})$ & & \\
\hline Chinese & $63(54.3)$ & $48(51.1)$ \\
\hline Malay & $30(25.9)$ & $28(29.8)$ \\
\hline Indian & $10(8.6)$ & $6(6.4)$ \\
\hline Others & $13(11.2)$ & $12(12.8)$ \\
\hline Site (p=1.000) & & \\
\hline Nodal & $53(45.7)$ & $43(45.7)$ \\
\hline Extranodal & $63(54.3)$ & $51(54.3)$ \\
\hline Lymphoma Subtype & & \\
\hline DLBCL, NOS & $57(49.1)$ & $50(53.2)$ \\
\hline Plasmablastic & $2(1.7)$ & $2(2.1)$ \\
\hline FL & $14(12.1)$ & $7(7.4)$ \\
\hline MZL & $8(6.9)$ & $8(8.5)$ \\
\hline MCL & $4(3.4)$ & $2(2.1)$ \\
\hline BL & $5(4.3)$ & $1(1.1)$ \\
\hline & & \\
\hline
\end{tabular}

\begin{tabular}{|l|l|l|}
\hline SLL & $1(0.9)$ & $2(2.1)$ \\
\hline Lymphoblastic Lymphoma & $2(1.7)$ & $1(1.1)$ \\
\hline B-cell NHL (No category) & $5(4.3)$ & $4(4.3)$ \\
\hline T-cell NHL & $7(6.0)$ & $3(3.2)$ \\
\hline HL & $11(9.5)$ & $14(14.9)$ \\
\hline
\end{tabular}

nodal was $44 \%$. Chinese had the most with $61.3 \%$ compared to Malay (21.3\%), Indian (5.3\%) and others (12\%). While, the top three common NHL subtype for the $\geq 60$ years age group were DLBCL NOS (64\%), MZL (12\%) and the third common type were both $\mathrm{FL}$ and $\mathrm{MCL}$ with $5.3 \%$ each.

\section{Gender}

Table 2 showed gender analysis of patients with respect to age, ethnic, site of lymphoma and lymphoma subtypes. There were 116 males (55\%) compared to 94 females (45\%) with the male to female ratio of 1.2:1. The median age for both males and females were similar with 51 years while the age range was between 8 to 80 years for males and 8 to 92 years for females. There were more Chinese males (54.3\%) compared to females $(51.1 \%)$ and there were also more Indian males (8.6\%) 
Table 3: Ethnic analyses.

\begin{tabular}{|c|c|c|c|c|}
\hline & $\begin{array}{l}\text { Chinese } \\
\mathrm{N}=111(\%)\end{array}$ & $\begin{array}{l}\text { Malay } \\
\mathrm{N}=58(\%)\end{array}$ & $\begin{array}{l}\text { Indian } \\
\mathrm{N}=16(\%)\end{array}$ & $\begin{array}{l}\text { Others } \\
\mathrm{N}=25(\%)\end{array}$ \\
\hline \multicolumn{5}{|l|}{ Age } \\
\hline Median (Range) & $54.1(10-92)$ & $45.2(8-78)$ & $54.8(33-83)$ & $50(8-73)$ \\
\hline \multicolumn{5}{|l|}{ Gender $(p=0.839)$} \\
\hline Female & $48(43.2)$ & $28(48.3)$ & $6(37.5)$ & $12(48.0)$ \\
\hline Male & $63(56.8)$ & $30(51.7)$ & $10(62.5)$ & $13(52.0)$ \\
\hline \multicolumn{5}{|l|}{ Site $(p=0.656)$} \\
\hline Nodal & $54(48.6)$ & $25(43.1)$ & $8(50.0)$ & $9(36.0)$ \\
\hline Extranodal & $57(51.4)$ & $33(56.9)$ & $8(50.0)$ & $16(64.0)$ \\
\hline \multicolumn{5}{|l|}{ Lymphoma Subtype } \\
\hline DLBCL, NOS & $51(45.9)$ & $34(58.6)$ & $6(37.5)$ & $16(64.0)$ \\
\hline Plasmablastic & $3(2.7)$ & $0(0.0)$ & $1(6.3)$ & $0(0.0)$ \\
\hline FL & $13(11.7)$ & $5(8.6)$ & $2(12.5)$ & $1(4.0)$ \\
\hline MZL & $10(9.0)$ & $2(3.4)$ & $0(0.0)$ & $4(16.0)$ \\
\hline MCL & $4(3.6)$ & $0(0.0)$ & $1(6.3)$ & $1(4.0)$ \\
\hline $\mathrm{BL}$ & $2(1.8)$ & $3(5.2)$ & $1(6.3)$ & $0(0.0)$ \\
\hline SLL & $1(0.9)$ & $1(1.7)$ & $1(6.3)$ & $0(0.0)$ \\
\hline Lymphoblastic Lymphoma & $1(0.9)$ & $2(3.4)$ & $0(0.0)$ & $0(0.0)$ \\
\hline B-cell NHL (No category) & $6(5.4)$ & $2(3.4)$ & $0(0.0)$ & $1(4.0)$ \\
\hline T-cell NHL & $9(8.1)$ & $0(0.0)$ & $1(6.3)$ & $0(0.0)$ \\
\hline $\mathrm{HL}$ & $11(9.9)$ & $9(15.5)$ & $3(18.8)$ & $2(8.0)$ \\
\hline
\end{tabular}

compared to Indian females (6.4\%). However, more Malay females (29.8\%) were recorded compared to Malay males (25.9\%). In terms of lymphoma sites, both male and female had more extranodal cases (54.3\%) compared to nodal cases (45.7\%). For the association of gender in terms of ethnic and lymphoma site, there was no significant difference found in any with $(p=0.839)$ and $(p=1.000)$ respectively.

For the NHL subtype, DLBCL NOS had more percentage cases in females (53.2\%) compared to males (49.1\%) while FL had more cases in males $(12.1 \%)$ than females (7.4\%). Similarly, MCL, BL and T-cell NHL had more cases in males than females. In the other hand, there were eight cases each in males and females for MZL as well as plasmablastic with two cases each in males and females. While for $\mathrm{HL}$, females had more cases (14.9\%) than males $(9.5 \%)$.

\section{Ethnicity}

Table 3 summarized the ethnic analyses in terms of age, gender, site of lymphoma and lymphoma subtypes. Chinese recorded the highest prevalence among other ethnicities with 111 cases (53\%) followed by Malays with 58 cases $(27 \%)$, Others which consists of Bumiputeras (Indigenous) and foreign patients with 25 cases (12\%) and lastly Indian with 16 cases (8\%). Malay had the least median age with 45.2 compared to other ethnicities with at least median age of 50 . While, the largest age range was Chinese with 10 to 92 years and the least age range was Indian with 33 to 83 years. There
Table 4: NHL low-grade and high-grade.

\begin{tabular}{|l|l|l|}
\hline & Low-Grade NHL & High-Grade NHL \\
\hline $\mathbf{N}=\mathbf{1 7 6}, \mathbf{( \% )}$ & $46(26.1 \%)$ & $130(73.9 \%)$ \\
\hline Age median (Range) & $55.2(30-77)$ & $53.5(8-92)$ \\
\hline Gender $(\boldsymbol{p}=\mathbf{0 . 8 6 3 )}$ & & \\
\hline Female & $19(41.3 \%)$ & $57(43.8 \%)$ \\
\hline Male & $27(58.7 \%)$ & $73(56.2 \%)$ \\
\hline Ethnic $(\boldsymbol{p}=\mathbf{0 . 4 1 8})$ & & \\
\hline Chinese & $28(60.9 \%)$ & $66(50.8 \%)$ \\
\hline Malay & $8(17.4 \%)$ & $39(30.0 \%)$ \\
\hline Indian & $4(8.7 \%)$ & $9(6.9 \%)$ \\
\hline Others & $6(13.0 \%)$ & $16(12.3 \%)$ \\
\hline Sites $(\boldsymbol{p}=\mathbf{0 . 2 2 6})$ & & \\
\hline Nodal & $24(52.2 \%)$ & $53(40.8 \%)$ \\
\hline Extranodal & $22(47.8 \%)$ & $77(59.2 \%)$ \\
\hline
\end{tabular}

were at least $51 \%$ more males than females in all the ethnicities and similar cases was found whereby more extranodal sites (at least 50\%) was recorded compared to nodal across all ethnicities. However, there was no significance association found between ethnic with gender $(p=0.839)$ and ethnic with lymphoma sites ( $p$ $=0.656$ ). For Chinese ethnic, DLBCL NOS recorded the highest lymphoma subtype with $45.9 \%$ followed by $\mathrm{FL}$ (11.7\%) and $\mathrm{HL}(9.9 \%)$ as well as MZL (9\%). Meanwhile, Malays had $58.6 \%$ of DLBCL NOS, $15.5 \%$ of $\mathrm{HL}$ and the third highest was FL (8.6\%). Similarly, Indian also had the most cases of DLBCL NOS (37.5\%), HL (18.8\%) and 
FL (12.5\%). For others ethnic, DLBCL NOS recorded 64\% and MZL had $16 \%$.

\section{NHL low grade and high grade}

Table 4 showed the NHL low-grade and high-grade cases. The low-grade NHL cases consist of FL, MZL, MCL and SLL while the high-grade NHL cases were DLBCL NOS, plasmablastic Lymphoma, BL, Lymphoblastic Lymphoma and T-cell NHL. While, HL and B-cell NHL general category were excluded from the grading. There was a total of 176 cases with more high-grade NHL cases (73.9\%) than low-grade NHL (26.1\%). Low-grade NHL patients had a median age of 55.2 while high-grade NHL was 53.5. However, high-grade NHL had a larger age range (8-92) compared to low-grade NHL (30-77).

High-grade $\mathrm{NHL}$ had slightly more female patients $(43.8 \%)$ in contrast to low-grade $\mathrm{NHL}(41.3 \%)$ hence resulting in more male patients among the low-grade $\mathrm{NHL}$ (58.7\%) compared to males in high-grade NHL (56.2\%). There were more Chinese (60.9\%), Indian (8.7\%) and others $(13 \%)$ patients in the low-grade $\mathrm{NHL}$ cases but there were more Malay patients (30\%) in the high-grade NHL. In terms of lymphoma sites, nodal (52.2\%) was more in low-grade NHL while extranodal (59.2\%) was more in high-grade NHL. However, there was no significant association found between the $\mathrm{NHL}$ low-grade or high-grade in terms of gender $(p=0.863)$, ethnicity $(p=$ $0.418)$ and lymphoma sites $(p=0.226)$.

\section{Discussion}

In this report, we provide the incidence and prevalence of Non-Hodgkin lymphoma (NHL) from a private hospital in Kuala Lumpur, Malaysia. NHL is a malignant disease of the immune system with the most rapidly increasing incidence in many countries since the last seventy years [10]. The private hospital in this study is located in the capital city of Kuala Lumpur with a total population of approximately 1.7 million and estimation of 1.5 million Malaysian citizens [11]. The percentage of Kuala Lumpur population by ethnic group was $44.7 \%$ Malays, $43.2 \%$ Chinese, $10.3 \%$ Indian and $1.8 \%$ others. The ethnic distribution in our study found that Chinese patients (53\%) had the highest lymphoma cases compared to other races and this further supported the statistics done by Malaysia National Cancer Registry in 2007 [8]. The high percentage of Chinese lymphoma compared to other ethnic particularly in this hospital could be partly due to the higher utilization of the hospital facilities among Chinese ethnic in the surrounding area. However, this remains a suggested reason since there is no hospital admission data available to compare. In addition, Chinese ethnic are more susceptible to develop lymphoma and other type of cancers according to previous studies [12,13]. However, the study done in Sarawak [14] showed that among the races, Chinese are less risk in developing NHL and the occurrence of EBV-associated T/NK lymphoma in the Chinese popu- lation of Sarawak was very low.

It was revealed that in Malaysia high-grade DLBCL is the dominant subtype of NHL in comparison to low prevalence of FL [15]. The 51\% DLBCL patients in our study showed that DLBCL cases had increased up to $5 \%$ when compared with previous study done in a Malaysian public hospital 15 years ago [9]. In addition, our 51\% DLBCL cases was also higher than studies done in North America (29.3\%) but lower than studies done in Thailand with $59.3 \%$ or Indonesia with $60.1 \%$ [16]. It was also shown through our study that DLBCL was more common in Asia particularly Far East countries excluding Japan. In the other hand, the $10 \% \mathrm{FL}$ cases found in this study was lower compared to North America (33.6\%) but similar to the total of FL cases (9.4\%) in the Far East [16]. Kim, et al. [17] mentioned that FL was less frequently found in Asia compared to North America and Europe and that reports shown the $\mathrm{FL}$ rates are considerable low among Asian population $[18,19]$ as also displayed in this study. The MZL cases (7.6\%) in this study were also found to be lower in comparison to the data shown from United Kingdom with $17 \%$ [20]. Another NHL subtype, BL (2.6\%) was found to be considerably higher than those in United Kingdom (1.8\%) [20] and the rest of the Far East countries except Indonesia (6\%) [16]. While, MCL which presented $2.6 \%$ in this study was similar to studies done in China (2.6\%) [21] and Iran (2.2\%) [18]. HL was reported to be rare among Asian populations [22], however comparing the $\mathrm{HL}$ cases $(12 \%)$ in this study with those in Iran (8\%), Korea (5.3\%), Taiwan (7\%) and China (13.9\%), showed that there is a slight surge in $\mathrm{HL}$ incidence particularly in Asia.

According to SEER (Surveillance, Epidemiology and End Results), approximately 73,000 new cases of NHL was estimated in 2016 which constituted about $4.3 \%$ of all cancer cases [23]. Based on the United States cancer statistics, the estimated death caused by $\mathrm{NHL}$ in 2016 was 20,000 (3.4\% of all cancer deaths) and 71\% surviving more than 5 years [24]. Lymphoma affected more males than females and the incidence for $\mathrm{NHL}$ is increasing since the last seventy years in comparison to $\mathrm{HL}$ [25]. NHL is the eight-common cancer in men with $2.9 \%$ (about 220,000 new cases diagnosed) while it is the tenth most common cancer in women with $2.5 \%$ (168,000 cases) [4]. As opposed to the data found in Malaysia, NHL cancer incidence for male was $4.2 \%$ and female was $2.6 \%$ [7]. Our study had slightly more males (55\%) than females (45\%) with 1.2:1 ratio which coincided with NHL overall prevalence but the female patients in this study was found to be higher compared to those found in the Far East studies which was 37.7\% [16].

This study median age of 51 was found to be similar to the median age of $\mathrm{NHL}$ patient in Asian countries such as Iran [18], Korea [26] and Taiwan [27] are between 5055 years-old. In comparison to western countries, Asian countries have lower median age of NHL. The represen- 
tative median age of patient in western countries was 68-years-old [28]. In addition, the observed progressive increase in the incidence of DLBCL for patients aged 50 and above concurred with worldwide NHL incidence [6]. While, our DLBCL patients' age group of 40-60 (39.5\%) was almost similar to those found in Hispanic Whites (38.4\%) but higher than the Asian and Pacific Islanders with $32.8 \%$ [29]. In terms of lymphoma sites, evidences [30,31] have shown that incidence of extranodal are higher compared to nodal sites among Asian population. According to a study [32], extranodal sites such as gastrointestinal tract, nasal cavity and tonsils are the commonest sites, and this was also seen in our study with $54 \%$ presented in the extranodal sites and the rest of the $46 \%$ in the nodal sites.

As observed by Muller [33], both males and females has seen an increased in all age groups but there is racial differences observed in age-specific incidence curves until the age of 45 and 35 for male and female respectively. This was evident in this study as well. In addition, the lymphoma incidence rates only partly reflect varying data quality worldwide. This may be due to different prevalence of risk factors, wider use of immune-histochemical method for screening and diagnosing cancer cell type which leads to lesser misdiagnosis cases of NHL as well as better classification of grey-zone lymphomas. Apart from that, different staining and scoring values and populations may also cause variation in findings between countries.

In summary, the lymphoma pattern demonstrated in this private hospital found significance association in terms of ethnicity $(p=0.046)$ with relation to the patients' age groups. Malaysian lymphoma patients aged 50 and above had the most cases with males contracted the disease than females. In addition, extranodal lymphomas accounted for more than $50 \%$ of all $\mathrm{NHL}$ diagnosed in this retrospective study. One of the limitations of this study is that it may not serve as true representative epidemiological study of lymphoma in Malaysia. However, it can contribute information for future research on the incidence and pattern of Malaysian lymphomas which are currently not up to date. This is important as it can help to preclude the application of guideline and treatment strategies. Further studies such as that incorporated advanced molecular analyses or evaluations of polymorphisms in NHL patients among Malaysian multi-ethnic population will be interesting to clarify any underlying contributing factors.

\section{Acknowledgments}

Many thanks to Puan Rohaidah (Pantai Premier Pathology Lab), Fatin (Pantai Premier Pathology Lab), Sharon Teoh (UCSI University), Grace Ng and Pavitra Mahendran for their assistance.

\section{Competing Interests}

The authors have declared that no competing interests exist.

\section{Funding}

This work was funded by Malaysian Ministry of Higher Education (MOHE) Fundamental Research Grant Scheme (FRGS) FRGS/1/2014/SKK06/UCSI/01/1 and UCSI University Research Excellence \& Innovation Grant (REIG) REIG-FMS-2020/009. The funders had no role in study design, data collection and analysis, decision to publish, or preparation of the manuscript.

\section{Ethics}

The studies complied with all provisions of the Declaration of Helsinki and were approved by Medical Research Ethics Committee Malaysia and UCSI University Faculty of Medicine and Health Science Ethics Committee.

\section{References}

1. Swerdllow SH, Campo E, Harris NL, Jaffe ES, Pileri SA, et al. (2008) WHO classification of tumours of haematopoietic and lymphoid tissues. FRANCE: IARC PRESS.

2. (1982) $\mathrm{NCl}$ Non-Hodgkin's Classification Project Writing Committee. National Cancer Institute sponsored study of classification of non-Hodgkin's lymphomas: Summary and description of a working formulation for clinical usage. The Non-Hodgkin's Lymphoma Pathologic Classification Project. Cancer 49: 2112-2135.

3. Zucca E (2008) Extranodal lymphoma: A reappraisal. Ann Oncol 19: 77-80.

4. Ferlay J, Soerjomataram I, Dikshit R, Eser S, Mathers C, et al. (2015) Cancer incidence and mortality worldwide: Sources, methods and major patterns in GLOBOCAN 2012. Int J Cancer 136: E359-E386.

5. Ekström-Smedby K (2006) Epidemiology and etiology of non-Hodgkin lymphoma- a review. Acta Oncol 45: 258-271.

6. American Cancer Society (2015) Global Cancer Facts \& Figures. ( $3^{\text {rd }}$ edn). Am Cancer Soc 1-64.

7. Bray F, Ren JS, Masuyer E, Ferlay J (2013) Estimates of global cancer prevalence for 27 sites in the adult population in 2008. Int J Cancer 132: 1133-1145.

8. Omar ZA, Tamin NS (2011) National Cancer Registry Report 2007. Malaysia Cancer Statistics-Data and Figure, Kuala Lumpur: National Cancer Registry, Ministry of Health Malaysia 89.

9. Peh SC (2001) Host ethnicity influences non-Hodgkin's lymphoma subtype frequency and Epstein-Barr virus association rate: The experience of a multi-ethnic patient population in Malaysia. Histopathology 38: 458-465.

10. Baris D, Zahm SH (2000) Epidemiology of lymphomas. Current opinion in oncology 12: 383-394.

11. Department of Statistics Malaysia. Population Distribution and Basic Demographic Characteristics 2010.

12. Bosco J, Cherian R, Lin HP, Pang T (1985) Leukaemia and lymphoma in Malaysia. Leukemia Research 9: 789-791.

13. Seow A, Lee J, Sng I, Fong CM, Lee HP (1996) Non-Hodgkin's lymphoma in an Asian population: 1968-1992 time trends and ethnic differences in Singapore. Cancer 77 : 1899-1904.

14. Peh SC, Gudum HR, Tai YC, Wong FL, Dolkadir J (2001) Spectrum of Malignant Lymphoma in Sarawak General 
Hospital. J Clin Exp Hematop 41: 45-49.

15. Peh SC, Shaminie J, Jayasurya P, Hiew J (2003) Spectrum of malignant lymphoma in Queen Elizabeth Hospital, Sabah. The Medical journal of Malaysia 58: 546-555.

16. Perry AM, Diebold J, Nathwani BN, MacLennan KA, Müller-Hermelink HK, et al. (2016) Non-Hodgkin lymphoma in the Far East: review of 730 cases from the international non-Hodgkin lymphoma classification project. Ann Hematol 95: 245-251.

17. Kim CW, Kim IS, Ko YH, Cho HJ, Yang WI, et al. (1992) Clinicopathologic and immunophenotypic study of non-Hodgkin's lymphoma in Korea. Journal of Korean Medical Science 7: 193-198.

18. Mozaheb Z, Aledavood A, Farzad F (2011) Distributions of major sub-types of lymphoid malignancies among adults in Mashhad, Iran. Cancer Epidemiol 35: 26-29.

19. Li X, Li G, Gao Z, Zhou X, Zhu X (2011) The relative frequencies of lymphoma subtypes in China: A nationwide study of 10002 cases by the Chinese Lymphoma Study Group. In Annals of Oncology 22: 141. Great clarendon st, oxford, England: Oxford univ press.

20. Smith A, Crouch S, Lax S, Li J, Painter D, et al. (2015) Lymphoma incidence, survival and prevalence 2004-2014: Sub-type analyses from the UK's Haematological Malignancy Research Network. British Journal of Cancer 112 1575-1584.

21. Wang J, Young L, Win W, Taylor CR (2005) Distribution and ZAP-70 expression of WHO lymphoma categories in Shanxi, China: a review of 447 cases using a tissue microarray technique. Applied Immunohistochemistry \& Molecular Morphology 13: 323-332.

22. Mozaheb Z (2012) Epidemiology of lymphoid malignancy in Asia. INTECH Open Access Publisher.

23. Howlader N, Noone AM, Krapcho M, Garshell J, Neyman N, et al. (2013) SEER Cancer Statistics Review, 19752010, National Cancer Institute. Bethesda, MD.
24. Siegel RL, Miller KD, Jemal A (2015) Cancer statistics, 2015. CA: A cancer journal for clinicians 65: 5-29.

25. Horesh N, Horowitz NA (2014) Does gender matter in non-hodgkin lymphoma? Differences in epidemiology, clinical behavior, and therapy. Rambam Maimonides Med J 5: e0038.

26. Ko YH, Kim CW, Park CS, Jang HK, Lee SS, et al. (1998) REAL classification of malignant lymphomas in the Republic of Korea. Cancer 83: 806-812.

27. Lee MY, Tan TD, Feng AC, Liu MC (2005) Clinicopathological analysis of malignant lymphoma in Taiwan, defined according to the World Health Organization classification. Haematologica 90: 1703-1705.

28. Smith A, Roman E, Howell D, Jones R, Patmore R, et al. (2010) The Haematological Malignancy Research Network (HMRN): A new information strategy for population based epidemiology and health service research. British Journal of Haematology 148: 739-753.

29. Li Y, Wang Y, Wang Z, Yi D, Ma S (2015) Racial differences in three major NHL subtypes: Descriptive epidemiology. Cancer Epidemiol 39: 8-13.

30. Al Diab AR, Aleem A, Qayum A, Al Askar AS, Ajarim DS (2011) Clinico-pathological pattern of extranodal non-Hodgkin's lymphoma in Saudi Arabia. Asian Pac J Cancer Prev 12: 3277-3282.

31. Padhi S, Paul TR, Challa S, Prayaga AK, Rajappa S, et al. (2012) Primary extra nodal non Hodgkin lymphoma: A 5 year retrospective analysis. Asian Pac J Cancer Prev 13: 4889-4895.

32. Fadilah SAW (2009) Fundamentals of the management of non-Hodgkin lymphoma. Med J Malaysia 64: 333-340.

33. Müller AMS, Ihorst G, Mertelsmann R, Engelhardt M (2005) Epidemiology of non-Hodgkin's lymphoma (NHL): Trends, geographic distribution, and etiology. Ann Hematol 84: $1-12$. 